\title{
A EXPERIÊNCIA DA INTEGRAÇÃO EUROPEIA E SEU POTENCIAL PARA A INTEGRAÇÃO REGIONAL*
}

Philippe C. Schmitter

A experiência recente da Europa na integração - pacífica e voluntária - de Estados nacionais previamente soberanos numa única organização transnacional, a União Europeia, é de longe a tentativa mais significativa e de maior alcance em direção ao regionalismo. É, portanto, a que pode oferecer com maior probabilidade lições para aquelas regiões do mundo que estão apenas começando esse processo histórico complexo e sem precedentes.

Temos apenas um instrumento que pode nos ajudar a transferir conhecimento e lições de uma região para outra: a teoria. Apenas captando os conceitos genéricos, as hipóteses confirmadas e os processos observados subjacentes à experiência europeia que podemos ter a expectativa de contribuir para a compreensão das condições sob as quais a "formação de comunidades" regionais pode ter sucesso em

\footnotetext{
* Tradução de Plinio Dentzien. Este ensaio foi escrito originalmente como parte de uma pesquisa mais ampla no campo embrionário do "inter-regionalismo", isto é, a comparação de organizações transnacionais em diferentes regiões do mundo. Agradeço a colaboração de Sunyhuk Kim e Andrés Malamud por muitas das melhores ideias aqui contidas. As eventuais interpretações equivocadas são todas minhas.
} 


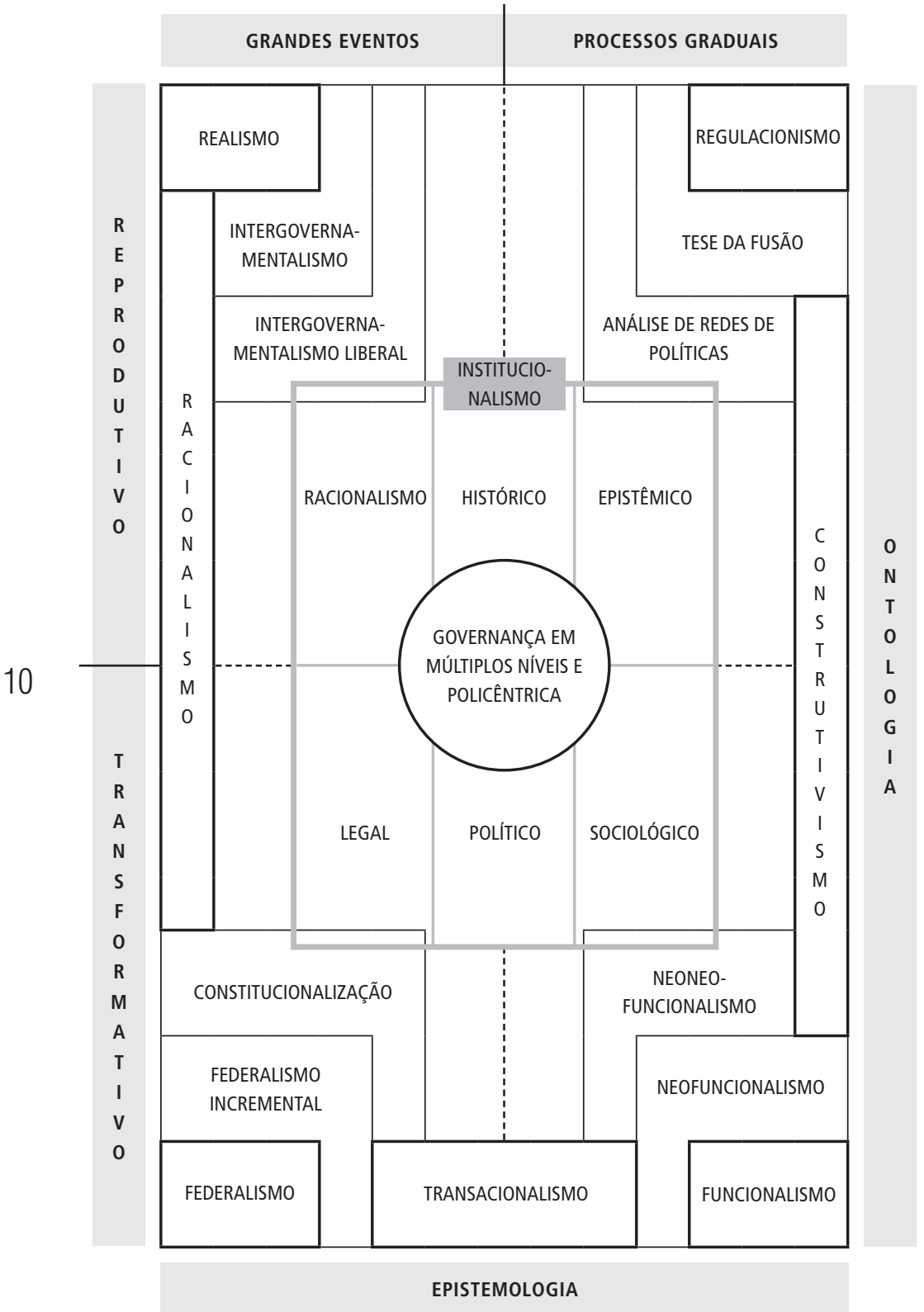


outros lugares. E, mesmo assim, dadas as diferenças substanciais entre as normas culturais, as experiências históricas, as estruturas sociais, a localização geoestratégica e os regimes políticos dessas regiões do mundo, há razões de sobra para cautela na transferência de tais lições.

\section{A diversidade de teorias sobre a integração europeia}

Infelizmente, não existe teoria dominante sobre por que e como funciona a integração regional europeia. É surpreendente que um processo que foi estudado em um nível tão concreto de detalhe continue a gerar tanta controvérsia abstrata. Há relativamente pouco desacordo sobre os fatos e mesmo sobre as motivações dos atores, mas ainda não há uma única teoria que possa explicar adequadamente a dinâmica (ou até mesmo a estática) de um processo tão complexo de mudança na relação entre Estados nacionais previamente soberanos e economias nacionais cada vez mais interdependentes.

A teoria, ou melhor, a abordagem com que tenho sido associado, e que apresentarei na segunda parte deste artigo com o intuito de formular as lições que podemos extrair da experiência da integração europeia, é a chamada "neofuncionalista", que pode ser localizada no canto inferior direito da Figura 1. No estabelecimento da dinâmica da integração adicional, ela dá maior ênfase ao papel de atores não estatais - especialmente ao "secretariado" da organização regional envolvida e aqueles movimentos sociais e associações de interesses que se formam em âmbito regional. Os Estados membros, que colocam os termos do acordo inicial, continuam como atores importantes no processo, mas não determinam exclusivamente a direção e o alcance da mudança subsequente. Ao contrário, são os burocratas regionais, aliados a um conjunto cambiante de interesses auto-organizados e paixões, que buscam explorar os inevitáveis "transbordamentos" e "consequências não previstas" 
que ocorrem quando os Estados concordam em delegar certo grau de responsabilidade supranacional para realizar uma tarefa limitada; assim, descobrem que satisfazer tal função tem efeitos externos sobre outras de suas atividades interdependentes. Segundo essa teoria, a integração regional é um processo intrinsecamente esporádico e conflituoso, mas que, em condições de representação democrática e pluralista, envolve cada vez mais os governos nacionais em pressões regionais e termina por resolver os conflitos entre esses governos pela concessão de maior alcance e atribuição de maior autoridade às organizações regionais que eles criaram. Eventualmente, seus cidadãos começarão a deslocar suas expectativas para a região e a satisfação dos mesmos aumentará a probabilidade de que a integração socioeconômica venha a se transformar em integração política ${ }^{1}$.

Entre os estudiosos da Comunidade Econômica Europeia/Comunidade Europeia/União Europeia, o funciona12 lismo não é, de forma alguma, incontestável em sua capacidade de explicar ex post ou captar ex ante o caminho sinuoso da integração europeia. Na verdade, ele tem sido o mais frequentemente mal-entendido, caricaturado, ridicularizado e rejeitado de todas as teorias.

Se houvesse uma teoria dominante entre os cientistas políticos norte-americanos, ela tenderia a ser o chamado "intergovernamentalismo". Isto muito provavelmente porque a maioria daqueles que estudaram a União Europeia nos Estados Unidos abordaram-na da perspectiva das relações internacionais, na qual a ortodoxia reinante, o neorrealismo, traduz-se, quase sem modificações, para o idioma e os pressupostos do intergovernamentalismo. Para essa

\footnotetext{
${ }^{1}$ O locus classicus da discussão é o livro de Ernst Haas (1958), seguido da apresentação mais sistemática de seus supostos, conceitos e hipóteses nos capítulos 1 e 2 de Beyond the Nation-State (Haas, 1964). Em pelo menos duas ocasiões (Haas, 1971; 1975), ele rejeitou sua criação. Mais recentemente, tentei ressuscitá-la em Schmitter (2003).
} 
perspectiva, a mensagem é simples: o poder importa e o poder de Estado, associado ao interesse nacional, importa absolutamente! A direção e o ritmo da integração regional serão determinados pela interação de Estados soberanos, que controlam não só o início do processo de integração, mas também todos seus estágios subsequentes. Que o processo se mova para frente ou para trás ou se estagne depende do cálculo dos interesses nacionais e do poder relativo que pode ser mobilizado em cada questão específica. Sob nenhuma circunstância, esse processo poderia transformar a natureza de seus Estados membros; seu propósito é fortalecê-los e não enfraquecê-los ${ }^{2}$.

Os europeus tendem a tratar a União Europeia da perspectiva da política comparada. Isso ajuda a explicar por que, enquanto não concordam sobre uma teoria dominante a respeito de como e por que funciona sua integração, optam por linhas de pesquisa diferentes daquelas predominantes nos Estados Unidos. Por exemplo, a abordagem original, posterior à Segunda Guerra, foi o federalismo, tomado de empréstimo, deve-se admitir, da experiência norte-americana. Há muito mantido à margem, como impulso ideológico foi recentemente ressuscitado com a convocação, pela União Europeia, da Convenção sobre o Futuro da Europa e a elaboração do Tratado que Estabelece uma Constituição para a Europa ${ }^{3}$.

Uma quarta abordagem "genérica", atualmente bem representada em alguns lugares da Europa, enfatiza a natureza regulatória das políticas da União Europeia. Note-se que ela também baseia grande parte de sua inspiração nos Estados

\footnotetext{
2 Assim como o neofuncionalismo poderia ser rotulado de "teoria de Berkeley" da integração regional, o intergovernamentalismo tem sido consistentemente associado com pesquisadores de Harvard. Stanley Hoffmann (1966) realizou a salva de abertura, e a mais recente foi a de Andrew Moravcsik (1998).

${ }^{3}$ Michael Burgess (1989) produziu a formulação padrão (ainda que antiga) sobre o tema.
} 
Unidos, ou melhor, na prática governamental de "agências reguladoras independentes", mas projeta suas noções e observações para o nível supranacional. Como o neofuncionalismo, dá atenção às micro e médias relações entre atores subnacionais e, desse modo, evita a ênfase exclusiva que o intergovernamentalismo dá aos tratados e que o federalismo dá às constituições; mas nega qualquer potencial transformador à regulação supranacional. Esta é compreendida como um imperativo tecnocrático gerado por economias e sociedades altamente interdependentes, mas não como algo que mudaria a natureza básica ou a autonomia da política nacional ${ }^{4}$.

Contudo, como se pode ver na Figura 1, há muitas outras candidatas para a tarefa de explicar e, assim, produzir lições genéricas sobre integração regional. Especialmente desde que foi relançada em meados dos anos 1980 com o Ato Único Europeu, a União Europeia se tornou mais uma vez um lugar muito vívido de especulação teórica. Raramen14 te se passa um ano sem que alguém não apareça com uma nova teoria e até, de modo mais surpreendente, não consiga convencer outro grupo de pesquisadores a produzir um volume coletivo exaltando suas virtudes. A "análise de regimes internacionais", a "abordagem regulatória", o "intergovernamentalismo liberal”, a "abordagem das redes de políticas", a "tese da fusão", a "governança em múltiplos níveis", o "institucionalismo", o "racionalismo", o "construtivismo", o "reflexivismo" e o "pós-modernismo" seguiram-se uns a outros ao longo dos últimos anos e encontram seu lugar em algum ponto da Figura 1. E essas disputas sobre conceitos e supostos não é meramente acadêmica. Como veremos, é possível extrair lições muito diferentes para outras regiões do mundo a partir de cada uma dessas teorias ou abordagens. Uma das principais tarefas de qualquer pesquisador que tente avaliar as perspectivas da integração regional em

\footnotetext{
${ }^{4}$ Giandomenico Majone (1966) foi quem melhor formulou esse argumento.
} 
qualquer lugar é selecionar a teoria (ou as teorias) na Figura 1 que é (são) a(s) mais oposta(s) às peculiares condições dessa região embrionária.

Em minha opinião, todas as teorias de integração regional podem ser colocadas dentro de um espaço de propriedades bidimensional formado pelas seguintes variáveis:

1. Ontológica: se a teoria presume um processo que reproduz as características existentes dos Estados membros participantes e do sistema interestados de que eles fazem parte, ou presume um processo que transforma a natureza desses Estados nacionais soberanos e de suas relações entre si; e

2. Epistemológica: se a evidência coletada para monitorar esses processos foca principalmente os eventos políticos dramáticos ou as prosaicas relações socioeconômicas e culturais.

A Figura 1 preenche esse espaço de propriedades com "ismos" da vida real que foram aplicados em diferentes momentos do tempo e a partir de diferentes perspectivas disciplinares para explicar a dinâmica (e a estática) da União Europeia. De maneira apropriada, encontramos o funcionalismo, com suas versões neo e neoneo, no canto inferior direito da distribuição. Sua ontologia é transformativa, pois ele supõe que tanto os atores como os "jogos que eles jogam" mudarão significativamente no curso do processo de integração; sua epistemologia se enraíza na observação de trocas graduais, normais e (em termos amplos) não obstrucionistas entre uma ampla gama de atores. Seu oponente histórico, o realismo, com suas modificações intergovernamentais puras e intergovernamentais liberais, opõe-se diametralmente a ele, dado que seus principais pressupostos são os de que os atores dominantes continuarão sendo os Estados nacionais 
soberanos perseguindo seus interesses nacionais unitários e controlando o ritmo e os resultados através de revisões periódicas de suas mútuas obrigações derivadas de tratados. O federalismo é outra opção transformadora, mas ele também se apoia em "momentos" episódicos em que uma multidão de atores (e não só seus governos) concorda sobre um novo formato constitucional. Seu oposto polar é o que chamei de "regulacionismo". Ele partilha com o intergovernamentalismo a hipótese de um continuísmo fundamental nos atores com apenas uma mudança ascendente no nível em que ocorre a regulação. Os Estados membros, porém, permanecem os mesmos, assim como sua motivação e sua influência predominante sobre o processo. O foco empírico difere na medida em que, como o funcionalismo, ele dá ênfase quase que exclusivamente às trocas socioeconômicas e à administração "normal" de suas consequências.

No centro do espaço de propriedades da Figura 1, 16 encontra-se uma coisa enorme e amorfa chamada "institucionalismo". Ele atribui orgulhosamente a si mesmo a maior parte do crescimento da teorização recente sobre a integração europeia e regional em geral e imediatamente alerta o leitor para o fato de que há muitas versões diferentes "de si mesmo". Em minhas contas, há seis: 1) uma "racional”, que se sobrepõe frouxamente ao intergovernamentalismo liberal em sua insistência sobre atores unitários, cálculos marginalistas e compromissos críveis; 2) uma "legal", que sublinha o papel gradual e intrusivamente federalista das decisões e precedentes jurídicos; 3) uma "histórica", que põe ênfase na "aderência" das identidades e na "dependência dos caminhos trilhados" por parte das instituições, mas não é insensível a processos menos óbvios de mudança; 4) uma "epistêmica", que foca as comunidades normativas e profissionais que se reúnem em torno de arenas específicas de questões e influenciam a feitura e implementação de regulações; 5) uma "política", que situa uma fonte de 
transformação potencial na criação de redes interpessoais de políticos importantes e sua autonomia relativa em relação a seus seguidores; e, finalmente, 6) uma "sociológica", que se sobrepõe ao neofuncionalismo em sua ênfase sobre a formação de associações transnacionais de classe, setoriais e profissionais e na contestação gerada pelos movimentos sociais globais e regionais. É discutível que alguma ou todas essas tendências mereçam o título de teoria. O institucionalismo enquanto tal tem apenas um conteúdo mínimo ("as instituições importam” é o lema que parece capturá-lo e esgotá-lo), mas pelo menos alguns de seus subtipos merecem o rótulo de "abordagem".

No próprio centro dessa coisa amorfa chamada "institucionalismo", na Figura 1, aparece a "Governança em Múltiplos Níveis" (GMN). A GMN pode ser definida como um arranjo para tomar decisões duradouras que envolve uma multiplicidade de atores - privados e públicos - politicamente independentes, mas de outras maneiras interdependentes, em diferentes níveis de agregação territorial, em negociações/deliberações/implementações mais ou menos contínuas, e que não atribui competências exclusivas sobre as políticas e nem afirma uma hierarquia estável de autoridade política a qualquer um desses níveis.

Opto por sublinhar também a natureza "policêntrica" tanto como os "múltiplos níveis" da União Europeia a fim de incluir a dimensão funcional ao lado da territorial. A Governança Policêntrica (GP) pode ser definida como um arranjo para tomar decisões permanentes entre uma multiplicidade de Estados membros, que delegam autoridade sobre tarefas funcionais a um conjunto de agências dispersas e relativamente autônomas que não são controladas - de jure ou de facto - por uma única instituição regional coletiva.

GMN tornou-se o rótulo onipresente e mais aceitável que se pode atribuir à União Europeia contemporânea. Até seus próprios políticos a usam! Penso que sua popularida- 
de entre os teóricos pode ser atribuída à sua neutralidade descritiva e, portanto, à sua compatibilidade putativa e virtual com qualquer das teorias institucionalistas e até mesmo várias de suas predecessoras mais extremas. Para os políticos, ela tem a vantagem singular de evitar o termo controverso "Estado" (especialmente, "Estado supranacional") e, portanto, soa menos proibitiva e ameaçadora. Por exemplo, o surgimento da GMN + GP a partir do processo da integração europeia pode ser (em parte) explicado por quase todas as teorias na Figura 1.

\section{Doze lições a partir da experiência europeia}

As "lições" esboçadas abaixo foram extraídas principal, mas não exclusivamente, de uma leitura neofuncionalista do curso sinuoso da integração europeia. Com uma restrição muito importante: ainda estou convencido de que essa abordagem oferece a melhor compreensão desse processo a longo 18 prazo. O início da integração regional, em qualquer lugar, requer um acordo explícito entre governos. Ninguém pode negar que as instituições e esferas de competência adotadas inicialmente terão um impacto contínuo em sua trajetória subsequente. Além disso, há grande probabilidade de que os Estados nacionais que concordam com esse tratado fundador fazem-no com a expectativa de que ele protegerá e até fortalecerá sua soberania, mas não a transformará. O que acontece depois de iniciado o processo de integração, e que gera consequências previstas e imprevistas, pode ser uma questão inteiramente diferente.

1. A integração regional é um processo e não um produto.

Uma vez iniciada, a integração pacífica e voluntária de Estados nacionais previamente soberanos pode seguir múltiplas direções e produzir efeitos secundários e terciários não imaginados por aqueles que a iniciaram. Precisamente porque é uma ocorrência tão pouco frequente, ninguém pode 
predizer quão longe ela irá e qual será eventualmente seu resultado. Além disso, quando Estados nacionais assumem um compromisso sério de formar uma "região", é provável que mudem seus motivos para fazê-lo. Eles podem começar com razões neoestratégicas e de segurança (a Europa Ocidental o fez) e então encontrar outras aplicações para sua associação, por exemplo, a prosperidade econômica e, de modo mais recente e conflitante, a unidade de ação política. Não há garantia de que o esforço inicial terá sucesso (de fato, a maior parte das tentativas de integração regional fracassou). Dependendo das condições prevalentes entre e dentro dos Estados membros, ele pode "transbordar" - para usar o jargão do neofuncionalismo. Contudo, sob certas condições (e a Europa Ocidental parece tê-las preenchido), os atores têm maior chance de resolver os inevitáveis conflitos de interesse que surgem do processo de integração, o que amplia as tarefas e aumenta a autoridade de suas instituições supranacionais comuns. Esse é, essencialmente, o núcleo da abordagem neofuncionalista.

2. A integração regional tem que começar em algum lugar e, nas condições contemporâneas, o melhor lugar para isso é numa área funcional com visibilidade política relativamente baixa, área essa com que aparentemente se pode lidar em separado e que pode gerar beneficios significativos para todos os participantes.

Depois de experimentar sem sucesso a rota "direta" de integração através de instituições políticas ou militares, os europeus tentaram a segunda melhor rota, a indireta; e isso (mais ou menos) funcionou. O ponto de partida contemporâneo será provavelmente diferente (os europeus começaram com carvão e aço; ninguém hoje em dia chegaria a pensar nessa combinação), mas a estratégia é bem captada pela frase de Jean Monnet: "petits pas, grands effets"; numa tradução livre, "pequenos passos, grandes efeitos”. Quer-se uma tarefa concreta que possa ser administrada em con- 
junto com poucas controvérsias iniciais, mas que é suficientemente ligada a outras ("engrenagem" é a palavra usada para isso) de forma a gerar efeitos secundários sobre outras áreas de cooperação potencial. A aposta é que os conflitos gerados pela tentativa de realizar essa tarefa inicial serão resolvidos de maneira positiva. No caso da União Europeia, a integração setorial foi seguida pela liberação do comércio e pela Política Agrícola Comum e, apenas tardiamente, pela integração monetária. Em outros lugares, a sucessão pode ser diferente, mas o ponto importante é a necessidade de se começar com algo que envolva cooperação para resolver problemas concretos de maneira positiva. Apenas a liberação comercial - as chamadas "Áreas de Livre Comércio" dificilmente produzem tais efeitos de "transbordamento".

3. A integração regional é dirigida pela convergência de interesses, e não pela formação de uma identidade.

20 Regiões internacionais são construções artificiais. Elas são produzidas, não descobertas. Alguns dos conjuntos de Estados nacionais que mais compartilham em termos de idioma, religião, cultura e experiência histórica foram os que tiveram menos sucesso na criação e desenvolvimento de organizações de integração regional; por exemplo, o Oriente Médio, as Áfricas do Norte, Ocidental e Oriental, a América Central e a do Sul. Ironicamente, foi a Europa - com seus múltiplos idiomas, culturas nacionais firmemente estabelecidas e uma terrível experiência de conflitos armados - a que mais avançou, embora seja importante observar que o processo de sua integração regional tenha se tornado cada vez mais contro-

\footnotetext{
${ }^{5}$ Em outro lugar, defini a hipótese do "transbordamento" da seguinte maneira: "Tensões a partir do ambiente global e/ou contradições geradas pelo desempenho passado (dentro da organização) dão surgimento a um desempenho não previsto na perseguição dos objetivos acordados. Essas frustrações e/ou insatisfações podem resultar na busca de meios alternativos de alcançar os mesmos objetivos, isto é, induzir ações para revisar suas estratégias respectivas em relação ao escopo e nível da tomada de decisões regional." (Schmitter, 1970, p. 243).
} 
verso e ninguém tenha sido capaz de discernir onde, quando e com quem ele acabará. Quando nada, a União Europeia demonstra que foi possível "fazer a Europa sem europeus". Frustraram-se aqueles que previam que o esforço combinado para resolver problemas concretos, o aumento da interdependência econômica ou a comunicação social mais fácil através das fronteiras nacionais, produziriam um declínio das identidades nacionais e uma mudança de lealdades. É certo que a importância das identidades nacionais diminuiu (exceto em relação a partidas de futebol) e que os europeus parecem confortáveis com identidades múltiplas e sobrepostas, as quais também descendem a níveis subnacionais e ascendem a níveis supranacionais. É certo também que os estilos de vida pessoal, os modos de comportamento social e as normas de ação política convergiram dentro da Europa. Se isso foi produto do processo de integração ou de uma difusão mundial mais ampla centrada nos Estados Unidos, está em debate. Aqueles que, como Ernst Haas, previram uma mudança de lealdades para o nível supranacional estão desapontados; aqueles que, como eu, esperavam uma mudança de modo que apenas se chamasse a atenção para o nível da União Europeia, se dão por satisfeitos quando a integração introduz um foco de interesse duradouro e significativo. Independentemente de saber como, quando e até mesmo se o regionalismo transcenderá as identidades nacionais, o importante neste meio tempo é que os europeus sabem, compreendem e aceitam que muitos de seus interesses só podem ser satisfeitos por processos que transcendem as fronteiras nacionais.

4. A integração regional pode ser pacífica e voluntária, mas não é linear nem isenta de conflitos.

A estratégia neofuncionalista (também conhecida no dialeto euro como "o método de Monnet") envolve focar tanto quanto possível as questões menos controversas e de baixa visibilidade, aquelas que podem ser separadas da política normal, 
isto é, da partidária. À medida que surgem conflitos de interesses, eles são decompostos e em seguida recompostos nos chamados "pacotes", que prometem benefícios para todos e que compensam os prováveis perdedores com pagamentos laterais em outros domínios. De modo independente das regras formais - mesmo agora, quando o voto qualificado da maioria se aplica a uma gama cada vez mais ampla de questões -, é feito todo o esforço para se alcançar um consenso. Quando tal solução não pode ser encontrada, a tomada de decisão do processo de integração hiberna por um período indeterminado. Nesse meio tempo, os processos de troca expandida continuam a produzir seus efeitos intencionais e não intencionais e, eventualmente, os participantes voltam à mesa. $\mathrm{O}$ aspecto mais visível do processo costuma ser a negociação periódica de novos tratados. Por mais importantes que sejam, eles não são nada além da manifestação superficial de um processo muito mais extenso que facilitou virtualmente as trocas entre 22 indivíduos, empresas e associações em todos os domínios da vida social, econômica e política e que resultaram na criação de grande número de organizações públicas e privadas em escala europeia. A persistência dessa estratégia é altamente problemática. A União Europeia esgotou as arenas de baixa visibilidade para coordenação política e as questões que ela enfrenta agora (por exemplo, harmonização fiscal, requisitos para vistos e asilo, cooperação policial, políticas externas e de segurança comuns), podem ser muito controversas. A crescente dificuldade com a ratificação de tratados aprovados por todos os governos membros é um claro sinal de "politização" e de sua penetração pela política partidária doméstica.

5. A integração regional deve começar com um pequeno número de Estados membros, mas deve desde o começo anunciar que está aberta a adesões futuras.

Além disso, é desejável que esse grupo inicial forme uma "área central”, para usar o termo de Karl Deutsch: devem 
ser espacialmente contíguos e ter uma alta taxa de intercâmbio entre eles. Se a área funcional e os membros forem bem escolhidos, isso deve resultar num aumento significativamente maior nas trocas entre si e um tratamento discriminatório daqueles deixados de lado. Desde que concordem sobre a distribuição interna dos benefícios e não se gerem facções permanentes (o que não é tarefa fácil), seu "sucesso" relativo atrairá os Estados vizinhos que escolheram não participar da região em seu estágio inicial. O processo de incorporação de novos membros coloca grande peso sobre as instituições, mas se torna um símbolo manifesto de que vale a pena unir-se à região. É especialmente crucial a capacidade de proteger o já adquirido durante essa ampliação e não diluir o conjunto acumulado de obrigações mútuas como meio de satisfazer interesses específicos dos novos Estados membros. É importante lembrar que as "regiões" não são preexistentes em algum sentido cultural, social ou econômico. Elas têm que ser criadas politicamente a partir da "matéria-prima" existente.

6. A integração regional envolve inevitavelmente Estados nacionais de tamanho e recursos de poder muito diferentes.

Como é um processo voluntário, os membros maiores e mais poderosos não podem simplesmente impor sua vontade - como fariam num sistema imperial. Eles têm que respeitar os direitos e a presença das unidades menores e mais fracas. No mínimo, isso implica firmes garantias sobre a continuação da existência deles, isto é, que o processo de integração não fará com que sejam "amalgamados" nos maiores. Isso parece exigir que as unidades menores sejam sistematicamente sobrerrepresentadas nas instituições regionais. Além disso, há um papel distintivo e positivo para os Estados menores no processo de integração, especialmente quando podem atuar como "Estados amortecedores" entre os maiores. Não é coincidência que os cidadãos 
daqueles Estados menores e menos desenvolvidos, quando entraram na União Europeia, tenderam a ser os seus mais fortes apoiadores.

7. A integração regional, porém, requer liderança, isto é, atores que sejam capazes de tomar iniciativas e estejam dispostos a pagar uma parte desproporcional dos custos delas.

A experiência europeia sugere que esse papel é mais bem desempenhado por um duopólio (França e Alemanha) do que por uma única potência hegemônica (Alemanha) ou por um tripólio (Alemanha, França e Grã-Bretanha). Ademais, é crucial que esses atores regionais líderes aceitem subutilizar seus recursos imediatos de poder (não obstante o neorrealismo e o intergovernamentalismo) a fim de investir na estratégia de longo prazo de legitimar o empreendimento como um todo. Felizmente para a integração da Europa, o hegemon potencial (Alemanha) tinha acabado 24 de sofrer uma derrota desastrosa na Segunda Guerra e se inclinava a minimizar seu papel. A França, a antiga grande potência, achou essa tarefa mais difícil e sua tendência a se automaximizar tem repetidamente ameaçado o processo de formação de consenso.

8. A integração regional requer um secretariado com poderes supranacionais limitados, mas potenciais.

Essa organização não só não deve ser percebida como instrumento de um dos membros (hegemônico), mas deve também ter certa medida de controle sobre a agenda do processo como um todo. A Comissão da União Europeia é composta de membros selecionados por um processo obscuro, firmemente enraizado na nomeação pelos governos nacionais. Porém, presume-se que, uma vez aprovados, devam seu comprometimento ao processo supranacional de integração e, portanto, não recebam instruções do corpo que os escolheu. Há evidência de que, por mais defeituoso 
que seja o procedimento de nomeação, os comissários tendem a adquirir a perspectiva "do colegiado" e a agir como agentes supranacionais. Além disso, o presidente da Comissão Europeia pode, sob circunstâncias admitidamente inusuais, não apenas afirmar seu monopólio na introdução de novas medidas, mas também desempenhar um papel proativo na determinação de quais devem ser tais medidas.

9. A integração regional requer que os Estados membros sejam democráticos.

Este é um fator que todas as teorias da integração europeia supõem. Também era suposto pelos primeiros proponentes até que, no início da década de 1960, a Espanha de Franco solicitou ingresso como membro da Comunidade Econômica Europeia, o que fez com que explicitamente se estipulasse que a "democracia doméstica" era um prerrequisito para o ingresso na organização. No Tratado de Amsterdã, ampliaram-se os prerrequisitos para cobrir o respeito aos direitos humanos e ao Estado de direito. Obviamente, ao se transferir as lições da integração para fora da Europa, isso não pode mais ser suposto: todas as demais regiões do mundo têm virtualmente dentro delas algumas não democracias.

Há (pelo menos) três razões pelas quais a democracia é necessária: 1) Apenas governos que têm forte legitimidade em suas sociedades nacionais podem assumir os "compromissos críveis" que são necessários para que eles participem de acordos, para ratificá-los de maneira conclusiva e para monitorar sua eventual implementação. No presente contexto, o único problema com respeito à legitimidade doméstica na Europa é a democracia parlamentar liberal. 2) A presença de um governo democraticamente responsável em todos os Estados membros é uma garantia suplementar de que nenhum deles recorrerá à força na resolução de disputas. Qualquer tentação que os governos mais poderosos tenham de extrair concessões, ameaçando membros 
recalcitrantes mais fracos, dificilmente seria apoiada por seus próprios cidadãos. 3) Se os neofuncionalistas estiverem certos, um elemento chave que levará adiante o processo de integração será a formação de associações de interesses e de movimentos sociais transnacionais e a intervenção dos mesmos na formação de políticas supranacionais. Apenas em democracias nacionais os cidadãos terão as liberdades necessárias para organizar tais formas de ação coletiva e criar vínculos com outras através das fronteiras nacionais. O fato de que, até a recente ampliação, todos os Estados membros eram não só democracias, mas praticavam formas semelhantes de democracia parlamentar (exceto pela França, com seu sistema semipresidencial) não parece ter sido importante; talvez porque também tinham sistemas muito diferentes de partidos e grupos de interesse, para não falar de governos de esquerda e de direita.

26 10. A integração regional parece possível com membros que estão em diferentes niveis de desenvolvimento e de riqueza per capita.

No começo, na Comunidade Econômica Europeia, apenas a Itália era marcantemente mais pobre e menos desenvolvida. A subsequente incorporação de Irlanda, Grécia, Portugal e Espanha reconfirmou a capacidade de a União Europeia não só acomodar essa óbvia fonte de tensão, mas também reagir a ela. Através de uma combinação de políticas - derrogações seletivas na entrada, fundos regionais e estruturais, subsídios agrícolas, além da pura dinâmica de mercados competitivos mais amplos -, ela promoveu um padrão que poderia ser chamado de "convergência ascendente". Aqueles Estados membros (e mesmo suas regiões subnacionais menos desenvolvidas e mais pobres) que entraram sob condições menos favoráveis tenderam a se dar melhor a partir de então e seus padrões de vida convergiram em direção da norma da União Europeia (e, em um caso, o da Irlanda, o ultrapassaram), sem, no entanto, diminuir o desempenho 
dos Estados membros mais favorecidos. A recente adição de dez membros testará severamente esse padrão tão afortunado. As diferenças iniciais na pobreza e subdesenvolvimento são maiores do que nas ampliações anteriores e, em alguns casos, contribuem para isso as diferenças estruturais na administração e nas relações de propriedade enraizadas na transição do socialismo "real" para o capitalismo "real". De qualquer modo, e ao contrário do pressuposto doutrinário segundo o qual a integração num mercado ampliado inevitavelmente aumentaria a distância entre unidades ricas e pobres (ver as histórias nacionais da Itália ou da Espanha), até aqui a União Europeia provou o oposto: a integração regional pode não só lidar com diferenças econômicas nacionais no ponto de partida, mas também diminuílas ao longo do tempo.

11. A integração regional é basicamente um processo endógeno, mas pode ser vulnerável a forças exógenas de modo crítico, especialmente em seus estágios iniciais.

Uma vez que um subconjunto de Estados nacionais concorda em criar uma "região", aceitando certas obrigações mútuas, e adotando uma organização comum de poderes específicos, seu sucesso ou fracasso ulterior é primeiramente uma questão de trocas entre esses Estados membros, e depois da influência de atores não estatais dentro de suas fronteiras e cada vez mais através delas. Obviamente, quanto mais poderes os Estados membros delegarem à organização regional, mais importante será o papel de suas lideranças e de sua administração. A experiência europeia, contudo, sugere que, em seus estágios iniciais, a integração regional pode depender muito de poderes externos. Mais precisamente, é duvidoso que o processo tivesse mesmo começado com a Comunidade do Carvão e do Aço em 1952 e com a Comunidade Econômica em 1958 sem a benevolente intervenção dos Estados Unidos. 
Aqui é onde a perspectiva "realista" e seu primo "intergovernamental" são especialmente relevantes. De forma presumível, existe uma configuração de poder e interesses no sistema mundial mais amplo que determina se e quando um ator hegemônico exógeno concluirá que prefere seus rivais mais integrados que desintegrados. Isso parece contrário à doutrina do divide et impera, a saber, quanto mais forte você é, mais você deve querer que seus oponentes estejam divididos para que não se reúnam para contestar o domínio estabelecido. Obviamente, o imperativo mais importante no caso da Europa Ocidental nos anos 1950 era o temor da União Soviética. Mas agora que esse imperativo não existe mais (e ainda não foi substituído pelo temor da China), a implicação parece clara: os Estados Unidos provavelmente verão menos favoravelmente os movimentos pela integração regional - pelo menos daqueles de que não participem ou que não possam controlar.

12. A integração regional, pelo menos até que esteja bem-estabelecida, é consumidora e não produtora de segurança internacional. Para dar sentido a essa afirmação, é preciso distinguir os pactos regionais de defesa e as organizações de integração. Em geral produto de uma potência hegemônica que expande sua capacidade de defesa sobre aquela de outros que lhe são subordinados (por exemplo, os Estados Unidos e a Otan, a União Soviética e o Pacto de Varsóvia), os primeiros estão orientados exclusivamente para a proteção da soberania externa de seus participantes por meios militares; já o propósito das últimas é superar ou, pelo menos, reunir a soberania interna de seus participantes, removendo as barreiras às trocas econômicas, sociais e políticas. Na Europa Ocidental, participação nas duas não coincidia e não era definitivamente obrigatória. A Comunidade Econômica Europeia/Comunidade Europeia/União Europeia teve sorte, em suas primeiras décadas, por existir "à sombra da 
Otan” e, portanto, por não ter que acrescentar a segurança externa à sua agenda já controvertida. Com o colapso da barreira entre a Europa Ocidental e a Oriental e o fim da Guerra Fria, o papel da Otan se tornou cada vez mais ambíguo e os Estados membros da União Europeia começaram - contra a resistência dos Estados Unidos - a elaborar sua própria capacidade para a segurança coletiva. Dada a enorme dificuldade de tal tarefa, é certamente positivo que suas instituições regionais "civis" já estejam bem-estabelecidas e reconhecidas - ainda que nem sempre amadas. O que é ainda mais fundamental para o sucesso da integração regional é a existência entre os Estados membros daquilo que Karl Deutsch et al. (1957) chamaram de uma "comunidade pluralista de segurança" 6 . Isso não requer instituições formais comuns, como uma aliança militar viável (de fato, ela pode existir com membros aliados e neutros), mas envolve um entendimento firme e confiável, ainda que informal, de que, sob nenhuma circunstância previsível, seus membros usarão ou ameaçarão usar força militar na resolução de disputas entre si. "Democracia doméstica" em todos os Estados membros é parte dessa garantia mútua (ao lado do respeito ao Estado de direito), mas é a prática diária de negociar e alcançar o consenso dentro das organizações regionais que torna crível esse entendimento.

\section{Doze observações sobre a aplicação das lições europeias a outros lugares}

Até agora nossa análise foi resolutamente eurocêntrica. Nossa (discutível) suposição foi a de que, se qualquer região transnacional quiser tornar-se integrada, ela deverá aprender a partir do padrão europeu e segui-lo. Além disso, definimos (sub-repticiamente) a integração em termos europeus, isto é,

\footnotetext{
${ }^{6}$ Ver também Richard W. Van Wagenen (1952).
} 
como e por que eles [Estados nacionais] se mesclam, se fundem e se misturam voluntariamente a seus vizinhos para perder os atributos factuais da soberania em troca de ganhar novas técnicas de resolver conflitos entre si (Haas, 1971, p. 6).

A esta definição clássica de Ernst Haas, apenas acrescentaríamos que eles o fazem criando instituições comuns e permanentes capazes de tomar decisões obrigatórias para todos os membros. Qualquer coisa além disso - aumentar os fluxos de comércio, encorajar contatos entre elites, tornar mais fácil que as pessoas se comuniquem ou se encontrem através de fronteiras, promover símbolos de identidade comum - pode tornar mais provável que a integração venha a ocorrer, mas nenhuma delas faz isso "pra valer".

Sob essas suposições, outras regiões do mundo (incluindo as Américas do Sul e Central) até agora fizeram pouco 30 progresso em direção à integração. Houve momentos de maior cooperação, solidariedade e identificação regional, mas não criaram um legado institucional de maior significação, nem tiveram sucesso em diminuir aqueles "atributos factuais da soberania” mencionados por Haas. Só contestando e mudando a definição do que constitui integração regional é que se poderia dizer que foi feito progresso nessas outras partes do mundo.

Diversos autores fizeram essa afirmação, a saber, de que há algum padrão "latino-americano", "asiático" ou "africano" de regionalismo que pode não se parecer ao padrão "institucional" europeu, mas que ainda assim seria capaz de resolver problemas regionais afirmando a coesão regional e construindo uma identidade regional. Discordamos. Acreditamos que essa é uma extensão equivocada da definição de "integração regional". A integração regional deve ser conceitualmente distinguida da cooperação ou colaboração regional não institucional e geralmente 
errática. Isso não quer dizer que isso seja impossível, apenas que será necessário aplicar as lições da Europa com muito cuidado.

1. A integração regional é um processo e não um produto.

$\mathrm{Na}$ busca da integração regional em outros lugares, como foi o caso com a integração europeia, nunca devemos supor que sabemos para onde estamos indo. Não só a finalidade política, mas também as econômicas ou sociais são imprevisíveis no momento da partida. O processo de integração regional, se ocorrer, é incerto e fortuito. Entretanto, ele deve ser pacífico, voluntário e - o que é mais importante - transformador. O processo deve alterar a motivação e os cálculos dos Estados nacionais, ampliar as tarefas funcionais que realizam coletivamente, aumentar a autoridade e a capacidade das instituições supranacionais e estimular a formação das associações de interesses e dos movimentos sociais através dos Estados membros. A esse respeito, um dos maiores problemas das Áreas de Livre Comércio (ALCs), que são atualmente tão populares nas novas adesões à Zona Euro, é que elas "parecem" ser e podem de fato ser "autossuficientes". Tais áreas dificilmente gerarão qualquer dos efeitos que se espera que um processo de integração produza, descritos na primeira parte deste texto. Ademais, a maior parte dos objetivos que se espera que as ALCs alcancem já são realizadas pelo Acordo Geral sobre Tarifas e Comércio e Organização Mundial do Comércio. Em suma, as ALCs regionais não são mais tão regionais. O chamado "regionalismo aberto", baseado numa série de ALCs sobrepostas, faz pouco ou nada para promover a integração.

2. A integração regional tem que começar em algum lugar e o melhor deles, nas condições contemporâneas, é o de uma área funcional de visibilidade política relativamente baixa, com a qual, 
aparentemente, pode-se lidar em separado; o que pode gerar beneficios significativos para todos os participantes.

Para que a integração regional avance, é necessário que os Estados membros tenham sucesso em promover a resolução coletiva de problemas concretos de maneira positiva. Essa é a principal lição proferida pelo teórico funcionalista original da integração, David Mitrany (1946). Desde o início, a integração não deve se ocupar somente da remoção de barreiras (integração negativa), mas também da criação de políticas comuns para regular e distribuir benefícios (integração positiva) (Scharp, 1996, pp. 15-39). Em relação à distribuição dos benefícios, a melhor, é claro, alcança o "ótimo de Pareto", quando todos ganham e ninguém perde. Mas isso é muito pouco realista. A distribuição de benefícios pode ser (e quase sempre é) desproporcional em certos momentos, mas é fundamental assegurar uma distribuição proporcional ou "justa" a longo prazo. Ato32 res participantes devem ser encorajados a pensar em termos de ganhos absolutos e não relativos. É extremamente importante selecionar uma área funcional que seja, no começo, indiscutivelmente "dissociável" e "interconectada”. Dissociável significa que a área deve ser capaz de se manter à parte e de gerar benefícios suficientes por si mesma. "Interconectada" significa que a área pode gerar efeitos secundários que requerem atenção e engendram coalizões de apoio positivas através das fronteiras. A liberalização do comércio é uma forma de integração "puramente negativa" e dificilmente produz efeitos de "transbordamento" de modo a contribuir para a integração regional. Além disso, as ALCs geram resistência demais por causa de interesses específicos (e às vezes com boas conexões) e deixam em aberto múltiplas oportunidades para fraudes e evasões em sua aplicação.

Será difícil encontrar o equivalente contemporâneo ao “carvão e aço” que deu início à Comunidade Econômica 
Europeia/Comunidade Europeia/União Europeia no começo dos anos 1950. Poderá ser o transporte (uma área funcional) ou, melhor, transporte e energia (duas áreas funcionais altamente inter-relacionadas). Em abstrato, elas parecem satisfazer todas as condições acima mencionadas, isto é, baixo nível de controvérsia, separabilidade e interconectividade.

3. A integração regional é dirigida pela convergência de interesses e não pela formação de uma identidade.

Regiões internacionais não existem, ainda onde tenham sido criadas e administradas como tais por uma potência colonial. Língua e religião comuns não parecem ser de grande ajuda. Antes, podem ser até um impedimento, porque ocultam diferentes "seitas" da mesma religião ou dialetos da mesma língua. Devemos ser igualmente cuidadosos em relação à noção de complementaridade dos economistas. A integração regional é um processo intrinsecamente dinâmico e gera especializações imprevistas e ascendentes, além de novas divisões do trabalho entre seus participantes. Daí que os padrões de comércio preexistentes podem não ser um bom indicador do potencial de gerar novas formas e níveis de interdependência.

É também importante que os Estados-nação se unam com uma motivação convergente, mas não idêntica. Eles devem "acertar" a integração por razões diferentes e com diferentes expectativas. Isso fornecerá o potencial futuro para criar "pacotes", que incluirão uma variedade de ganhos entre os participantes. Também os aumentos substanciais em comunicação social através das fronteiras nacionais parecem não ter (à Karl Deutsch) efeito automático sobre a integração. A diminuição na comunicação pode levar a identidades separadas, mas seu aumento não produz uma identidade comum. Ao contrário do que em geral se acredita, os antagonismos nacionais previamente intensos podem ser úteis para a integração - desde que haja um forte motivo 
para superá-los (em geral devido à existência de um novo inimigo comum). Mas os que aspiram à regionalização em outros lugares do mundo devem lembrar que identidade ou lealdade à região como um todo são um produto eventual e não um prerrequisito para a integração. Muito pode ser realizado, em outras palavras, antes que surja uma identidade ou lealdade comum.

4. A integração regional pode ser pacífica e voluntária, mas não é linear nem isenta de conflitos.

Desde o início, todos os participantes devem reconhecer a existência de conflitos entre eles. Mas isso não é o bastante: eles também devem esperar que esses conflitos sejam resolvidos pacificamente. Na verdade, a existência de conflitos é inevitável e pode ser explorada. Sem os conflitos, a integração regional não avançaria. De maior importância é a resposta à pergunta: Qual é o método esperado para resol34 ver esses conflitos? Quem elabora a fórmula vencedora? Uma das sugestões transferíveis da experiência europeia seria a de usar os conflitos (geralmente sobre a desigualdade na distribuição dos benefícios) para expandir - e não para contrair - o alcance e o nível da autoridade regional comum (supranacional). Muitos conflitos (mas não todos) só podem ser resolvidos aumentando os poderes do secretariado regional ou expandindo o alcance das atividades comuns (ou ambos), com compensações laterais aos perdedores. A regra da unanimidade é crucial no primeiro estágio, para dar segurança aos perdedores potenciais (especialmente se receberem volumes muito desiguais dos benefícios iniciais). Mas essa restrição pode ser afrouxada quando o avanço do processo de integração regional e das relações de confiança mútua entre os Estados nacionais membros for suficiente, de tal modo que uma firme crença na resolução pacífica de conflitos futuros possa ser gerada e alimentada. 
5. A integração regional deve começar com um pequeno número de Estados membros, mas deve desde o começo anunciar que está aberta a aderentes futuros.

A Comunidade Econômica Europeia começou originalmente com seis membros, mas estava aberta a outros. Não se deve presumir que a exclusão inicial é definitiva, embora seja útil para fins distributivos e de tomada de decisão ter um pequeno número no começo. A demonstração do "sucesso" da ampliação subsequente pode ser importante, assim como a perda de membros pode ser devastadora. Ao escolher os Estados membros, há dois fatores a considerar: 1) contiguidade espacial ("área central”) e 2) intercâmbio inicial relativamente alto ("relação de aceitação relativa"). $\mathrm{O}$ último é importante porque aumenta a "inveja" dos de fora. A regra da unanimidade, com tolerância, deve ser mantida na admissão de novos membros. A ambiguidade deliberada sobre fronteiras "regionais" também pode ser útil.

6. A integração regional envolve inevitavelmente Estados nacionais de tamanho e recursos de poder muito diferentes.

A clivagem de interesses fundamental no processo de integração tende a ser baseada no tamanho e no nível relativos de desenvolvimento. Essas características devem ser acomodadas em regras institucionais como, por exemplo, a sobrerrepresentação dos países menores, ao criar programas especiais para membros menos desenvolvidos. Deve haver uma garantia implícita ou explícita de que a integração regional não significa assimilação dos membros pequenos pelos maiores, ou dos menos desenvolvidos pelos mais desenvolvidos. O contrário é verdadeiro: a integração é muitas vezes a melhor garantia de sobrevivência para os Estados pequenos ou menos desenvolvidos. O melhor resultado imaginável é a "convergência", onde os membros mais fracos em desempenho econômico e político se descobrem crescendo rapidamente e tornando-se mais seguros relativamente àqueles 
fortes e estáveis. A questão mais difícil é a de como assegurar que os últimos concordem com tal redistribuição de renda e poder. O papel central nesse processo deve ser desempenhado pelo processo de adjudicação no nível regional (por exemplo, a Corte Europeia de Justiça). Isso assegurará que os grandes atores não dominem os pequenos. Também o secretariado da organização regional deverá desempenhar um papel proativo no controle das iniciativas e na montagem de coalizões que combinem tanto atores fracos como fortes. A compensação simbólica deve ser feita por meio de recursos como o do número de comissários e o da rotação da presidência da Comissão. Uma política de "garantias" deve também ser formulada não só contra a assimilação, mas também contra a desintegração intranacional. Regiões subnacionais devem receber apenas papéis limitados, e só com aprovação nacional. Além disso, as óbvias compensações que favoreçam os pequenos Estados também podem 36 ser feitas por meio de instituições regionais.

7. A integração regional, porém, requer liderança, isto é, atores capazes de tomar iniciativas e dispostos a pagar uma parte desproporcional do custo delas.

Isso está obviamente relacionado à questão anterior de tamanho e desenvolvimento. No padrão europeu, essas duas clivagens não coincidem, mas se atravessam. Alguns países pequenos são ricos e alguns grandes (relativamente) pobres. Em outros lugares, a situação pode ser mais complicada, isto é, quando os padrões iniciais de clivagem forem cumulativos. As perguntas importantes a responder são: 1) Por que o poder hegemônico, ou os dois ou três hegemons, desejariam pagar um preço mais alto para induzir os Estados menos favorecidos a participar?; e 2) O que pode induzi-los a subutilizar sua vantagem de poder inicial, permitindo mesmo que ela seja reduzida? No caso da dupla hegemônica, a estabilidade é importante, mas às vezes provoca estranheza entre os que 
chegam mais tarde. Um único hegemon "imperial" dentro da região pode ter um efeito inibidor no início - por exemplo, os Estados Unidos na Nafta ou o Brasil no Mercosul - especialmente se ele mostrar não ser "generoso" na concessão de benefícios aos outros.

8. A integração regional requer um secretariado com poderes limitados, mas potencialmente supranacionais.

Os poderes chave do secretariado, no caso da União Europeia, incluem: 1) controle sobre a iniciativa de novas propostas; 2) controle sobre a distribuição de posições em seu quase-gabinete (a Comissão Europeia); 3) discrição orçamentária; 4) potencial para levar os Estados membros para a Corte Europeia de Justiça; 5) possível monopólio de posição de rede e de informação, especialmente em relação a atores subnacionais (funcionais e territoriais); 6) alianças com o Parlamento Europeu; e 7) competência suficiente e independente para lidar com os "pacotes" e acordos nas diferentes áreas. Construir, financiar e equipar com pessoal um secretariado regional será provavelmente uma das prioridades em qualquer projeto regionalista viável e, até aqui, todas as tentativas de estabelecer um secretariado com tais poderes supranacionais fracassaram. Nenhuma instituição regional existente, com exceção da União Europeia, tem qualquer um dos poderes listados acima.

9. A integração regional requer que os Estados membros sejam democráticos.

Que os Estados membros sejam democráticos assegura que eles não usarão de força entre si, especialmente uma vez que a integração tenha progredido e suas respectivas sociedades civis tenham estabelecido inter-relações. Algumas garantias de legitimidade de governo e de tendência "centrípeta-centrista" na competição partidária são também essenciais para que os compromissos permaneçam não só 
constantes através dos partidos, mas também profundamente enraizados nas expectativas dos cidadãos. Deve-se notar, entretanto, que o paradoxo central da integração regional é que, embora ela requeira democracia, pelo menos nos primeiros estágios, essas democracias nacionais não devem estar atentas ou interessadas demais no processo de integração. Isso sugere que - nesses estágios iniciais - a existência de não democracias pode não ser necessariamente tão deplorável. Antes, a integração regional poderia ser promovida inicialmente pela cooperação entre autocracias estáveis e previsíveis e por democracias, na medida em que elas confiem entre si suficientemente para manter os compromissos e não recorram à força ou mesmo à ameaça do uso de força na resolução de disputas. Subsequentemente, a expansão da integração para novas áreas e seu aprofundamento, incluindo mais poderes para seu secretariado, poderá promover a democratização através de todos os Estados.

10. A integração regional parece possível com membros em diferentes níveis de desenvolvimento e de riqueza per capita.

A experiência europeia mostra não só que a integração regional é possível entre Estados nacionais membros com diferentes níveis de desenvolvimento, mas também que a convergência ascendente é possível para os países mais pobres e menos desenvolvidos. Em outras palavras, a integração não só pode lidar com disparidades regionais em seu ponto de partida, mas também diminuí-las ao longo do tempo. Virtualmente todas as regiões do mundo são compostas por países de níveis muito diferentes de desenvolvimento e de riqueza per capita. Os membros mais pobres e menos desenvolvidos devem ser persuadidos e convencidos de que sua participação nas iniciativas de integração regional é a melhor e mais segura estratégia para alcançar as economias mais avançadas da região e competir com elas. 
11. A integração regional é um processo basicamente endógeno, mas pode ser criticamente vulnerável a forças exógenas, especialmente em seus estágios iniciais.

A experiência europeia sugere fortemente que em seus primeiros estágios a integração pode ser altamente dependente de poderes externos. Em particular, é extremamente duvidoso que o processo tivesse chegado a começar sem a intervenção benevolente dos Estados Unidos. Na maioria das outras regiões do mundo, a influência dos Estados Unidos é maior devido à estrutura das alianças bilaterais gerada pela Guerra Fria e, após o término desta, mais tarde reforçada por sua hegemonia militar e econômica. Nas presentes condições, a tolerância, compreensão, concordância ou cooperação dos Estados Unidos parece essencial para o sucesso de qualquer movimento em direção da integração regional. Até agora, os Estados Unidos têm sido relativamente desatentos ou indiferentes aos vários projetos de integração, a menos que tenham um papel dominante neles.

12. A integração regional, pelo menos até que esteja bem-estabelecida, é consumidora e não produtora de segurança internacional.

Para muitas regiões do mundo, esta é a lição mais valiosa que vem da Europa. Sua integração foi desde o começo predicada sobre a existência prévia de uma putativa "comunidade de segurança" composta pelos países democráticos e essa condição foi também assegurada pela grande importância da Otan e dos Estados Unidos no fornecimento de um "guarda chuva de segurança" concreto para a região. Em outros lugares, a situação hoje é muito diferente a esse respeito: a maioria das regiões transnacionais inclui algumas não democracias, e abundam conflitos potencialmente violentos entre Estados membros potenciais. Animosidades, tanto históricas quanto contemporâneas, estão endemicamente presentes e são reacendidas erraticamente, muitas 
vezes como resultado de disputas políticas internas. Até que tenham sido resolvidas ou que tenham sua probabilidade reduzida, apenas os projetos regionais que deliberadamente excluam um ou ambos os Estados têm alguma chance de sucesso. Contudo, se tais esforços de exclusão tiverem sucesso, eles podem tornar-se úteis depois na resolução de conflitos quando a parte (ou as partes) excluída sofra relativamente às incluídas.

\section{Uma estratégia para integração regional em (quase) qualquer lugar}

1. Selecionar uma tarefa funcional (ou melhor, duas interrelacionadas). A tarefa escolhida deve ser dissociável, manifestamente difícil de realizar dentro dos limites de um só Estado nacional, e capaz de gerar benefícios concretos para todos os participantes num período relativamente curto de tempo. Duas tarefas funcionais são uma solução melhor

40 porque compensações podem ser negociadas entre elas.

1.1. Essa tarefa "dissociada" deve ter suficientes consequências possíveis de modo que, ao satisfazê-las coletivamente, os atores gerarão novas dificuldades em áreas relacionadas. Esse potencial de "transbordamento" será mais fácil de explorar se, no acordo original, os Estados nacionais participantes tiverem concordado em estabelecer um secretariado relativamente autônomo e com equipe internacional com um mínimo de autoridade supranacional, isto é, se for capaz de tomar decisões sem a necessidade constante do apoio unânime dos Estados membros.

1.2. O "transbordamento" é também mais provável se as tarefas envolverem uma variedade de agências estatais relativamente autônomas - e, especialmente, não só ministérios de relações exteriores que normalmente tentariam monopolizar as transações intergovernamentais - e se essas agências tiverem equipes técnicas e não só pessoal politicamente indicado. 
1.3. O desenvolvimento conjunto de infraestrutura de energia e transporte poderia fornecer um conjunto de funções apropriadas e aparentemente dissociadas nas circunstâncias atuais. $\mathrm{O}$ acordo sobre essas áreas não precisa exigir qualquer compromisso explícito de integração adicional, mas essas funções muito provavelmente gerarão pressão para tal "transbordamento". A ironia é que essas duas áreas funcionais figuraram entre as últimas em que a União Europeia foi capaz de gerar consenso e assumir ação coletiva.

2. Selecionar uma área central de unidades fisicamente contíguas com linhas de comunicação e intercâmbio e, se possível, motivos convergentes de cooperação.

2.1. Começar com o menor número de membros que sejam capazes de gerar benefícios materiais significativos em virtude de suas ações coletivas. Fazer com que seja relativamente fácil que outros Estados participem, mas apenas se concordarem em aceitar plenamente o que já tiver sido decidido. Não prejudica se a participação em tal organização regional também gerar uma melhora no status de seus membros em relação a outros Estados nacionais e regiões transnacionais.

2.2. Insistir no status igual e na soberania nacional de todos os participantes e renunciar a qualquer pretensão de utilizar essa cooperação funcional como mecanismo de unificação política. Em outras palavras, a "construção da região" deve ser claramente separada da "construção da nação".

3. Distribuir as agências regionais de tal forma que a maioria delas se localize em Estados membros menores ou menos desenvolvidos, mas com um secretariado composto conjuntamente por pessoas de todos os Estados membros.

4. A integração crescerá se a tarefa inicial (ou as tarefas iniciais) e a delegação (ou delegações) inicial de autoridade 
forem suficientes para atrair a atenção de interesses não estatais e der incentivos a que formem associações transnacionais de interesses ou movimentos sociais, demandando acesso às deliberações do secretariado regional. Isso obviamente depende de que todos os membros sejam democracias com direitos políticos e civis semelhantes.

5. Começar por projetos discretos e de baixa visibilidade a fim de não atrair a ira dos Estados Unidos, que provavelmente não terão a mesma "inclinação benévola" que tiveram nos casos da Comissão Europeia do Carvão e do Aço e da Comunidade Econômica Europeia. E, no entanto, buscar convencer os Estados Unidos de que tais esforços eventualmente contribuirão positivamente para seu objetivo mais amplo de segurança na região.

6. Estar preparados para pensar eventualmente, mas não 42 incorporar imediatamente, o "dilema da segurança".

7. Qualquer que seja a tarefa, e quaisquer que sejam os poderes da organização funcional, a integração ganhará na medida em que os atores nacionais e regionais envolvidos:

7.1. Desenvolverem relações de confiança mútua;

7.2. Desfrutarem de melhor status em seus respectivos governos e na comunidade internacional mais ampla;

7.3. Derem lições de resolução de problemas concretos a partir da cooperação;

7.4. Gerarem prêmios materiais significativos para os governos participantes e seus cidadãos;

7.5. Participarem na condição de igualdade formal no esforço, o que efetivamente significa que os Estados menores e mais fracos devem estar sobrerrepresentados na administração e tomada de decisões regionais;

7.6. Distribuírem os benefícios iniciais da cooperação e da interdependência de forma que não aquinhoem des- 
proporcionalmente os Estados maiores ou mais fortes; em outras palavras, os poderes hegemônicos devem estar dispostos a subsidiar os outros, mas não a fazê-lo abertamente.

Fazendo tudo isso, os interessados na integração regional terão uma chance razoável de promovê-la (para além da simples cooperação) em qualquer lugar do mundo. O que não quer dizer que será fácil.

\section{Philippe C. Schmitter}

é professor emérito do Instituto Universitário Europeu.

\section{Referências bibliográficas}

BURGESS, M. 1989. Federalism and European Union: political ideas, influences and strategies in the European Community. Londres: Routledge.

DEUTSCH, K. et al. 1957. Political community and the North Atlantic area. Princeton: Princeton University Press.

HAAS, E. 1958. The uniting of Europe. Stanford: Stanford University Press. . 1964. Beyond the Nation-State: functionalism and international organization. Stanford: Stanford University Press.

. 1971. "The study of regional integration: reflections on the joy and anguish of pretheorizing”. In: LINDBERG, L. N.; SCHEINGOLD, S. A. (orgs.). Regional integration: theory and research. Cambridge: Harvard University Press.

1975. The obsolescence of regional integration. Berkeley: Institute of International Studies.

HOFFMANN, S. 1966. "Obstinate or obsolete? The fate of the Nation State and the case of Western Europe”. Daedalus, vol. 95, no 3, pp. 862-915.

MAJONE, G. 1996. “A European regulatory State?”. In: RICHARDON, J. (org.). European Union: power and policy-making. Londres: Routledge.

MITRANY, D. 1946. A working peace system. Chicago: Quadrangle Books.

MORAVCSIK, A. 1998. The choice for Europe: social purpose and State power from Messina to Maastricht. Londres: UCL Press.

SCHARPF, F. W. 1996. "Negative and positive integration in the political economy of European Welfare States". In MARKS, G.; SCHARPF, F. W.; SCHMITTER, P. C.; STREEK, W. (orgs.). Governance in the European Union. Thousand Oaks: Sage. 
SCHMITTER, P. C. 1970. "A revised theory of regional integration". In: LINDBERG, L.; SCHEINGOLD, S. (orgs.). Regional integration: theory and research. Cambridge, MA: Harvard University Press. . 2003. "Neo-neo-funcionalism. Déjà-vu all over again". In: WIENER, A; DIEZ, T. (orgs.). European integration theory. Oxford: Oxford University Press.

VAN WAGENEN, R. W. 1952. Research in the international organization field: some notes on a possible focus. Princeton: Center for Research on World Political Institutions (Princeton University Publication n. 1). 


\section{A EXPERIÊNCIA DA INTEGRAÇÃO EUROPEIA E SEU POTENCIAL PARA A INTEGRAÇÃO REGIONAL}

\section{PHILIPPE C. SCHMITTER}

O artigo mostra que o processo de constituição da União Europeia representa um caminho significativo para o reforço do regionalismo. Assim, pode tornar-se modelo para outras tentativas políticas de integração regional. A reflexão sobre as diversas teorias que explicam esse fenômeno é a estratégia mais eficaz para examinar as possibilidades de transferência dessa experiência. O autor constrói um quadro classificatório que permite a avaliação dos pontos fortes e os mais débeis presentes nas diferentes propostas. O desafio que se coloca à análise é o de compreender a mudança na relação entre Estados nacionais previamente soberanos e economias nacionais cada vez mais interdependentes.

Palavras-chave: Integração europeia; Regionalismo; Poder supranacional; Regiões subnacionais; Regiões supranacionais; União Europeia; Neoneofuncionalismo.

\section{THE EXPERIENCE OF EUROPEAN INTEGRATION AND ITS POTENTIAL FOR REGIONAL INTEGRATION}

This paper shows that the process of constitution of the European Union represents a significant way of reinforcing regionalism. It can thus become a model for other political attempts at regional integration. A reflection on the various theories that account for this phenomenon is the best strategy to study the transposition of the European experience. The autor constructs a classification scheme that allows for the evaluation of the stronger and weaker points of the different approaches. The challenge is to understand the change in the relation among previously sovereign nation states and increasingly interdependent national economies. 
Resumos / Abstracts

Keywords: European integration; Regionalism; Supranational power; Sub-national regions; Supranational regions; European Union; Neo-neo-functionalism.

206 